\title{
Influence of the Load Models in the Dynamic Voltage Stability of an Electric Power System
}

\author{
R. M. Monteiro Pereira ${ }^{(1)}$, C. M. Machado Ferreira ${ }^{(1)}$, J. A. Dias Pinto ${ }^{(1)}$ \\ and F. P. Maciel Barbosa ${ }^{(2)}$ \\ ${ }^{1}$ Department of Electrical Engineering, Instituto Superior de Engenharia de Coimbra \\ Rua Pedro Nunes, Quinta da Nora, 3030-199 Coimbra, Portugal \\ phone: +351 239790 200, fax: +351 239790 201, e-mail: rmfm@isec.pt, cmacfer@isec.pt, ipinto@isec.pt \\ ${ }^{2}$ Faculdade de Engenharia da Universidade do Porto, Department of Electrical Engineering \\ R. Dr. Roberto Frias, 4200-465 Porto, Portugal \\ phone: +351 225081 819, fax: +351 225081 440, e-mail: fmb@fe.up.pt
}

\begin{abstract}
Voltage stability plays a very important role during the planning and design stages of an electric power network as well as during the system operation. In the last years in various countries worldwide, several power network collapses (blackouts) caused by voltage problems have been reported. This can be produced by a lack of sufficient reactive power reserve during heavy load or by the occurrence of severe contingencies. In this paper it is studied and analysed the influence of the load models in the dynamic voltage stability assessment of an electric power system. It was used the BPA test power network. A severe contingency situation was simulated to perform the study. The automatic voltage regulators of the generating units and the turbine speed governors were modelled as well as the transformer taps. The simulation results were obtained using the commercial transient software package EUROSTAG. Finally some conclusions that provide a better understanding of the voltage collapse phenomena are pointed out.
\end{abstract}

\section{Key words}

Electric Power System, Voltage Stability, Voltage Collapse, Load Models

\section{Introduction}

Most power systems are nowadays operated very near to their operating limits due to increase in consumption, while economic and environmental constraints have limited construction of new generation facilities and lines [1]. On the other hand, the change in the power system industry, with competition and liberalization of the energy market, increased the pressure on system operation, demanding new procedures and tools for online voltage stability assessment and identification of preventive control actions [2].

Voltage stability has become of the most important power system research areas. A lot of effort has been focused upon the cause and mechanism of voltage instability, and corresponding counter-measures [3].
Voltage stability is essentially a dynamic phenomenon and is affected by voltage control and load characteristics under voltage fluctuations [4].

This paper is devoted to the study and analysis of the influence of the load models in the dynamic voltage stability assessment of an electric power system. In the simulations it was used the BPA (Bonneville Power Administration) test power network, considering a severe contingency situation [5]. The automatic voltage regulators of the generating units and the turbine speed governors were taken into account as well as the transformer taps. The simulation solution were obtained using the commercial transient software package EUROSTAG developed by Electricité de France and Tractebel Energy Engineering.

\section{Applied software}

The simulations were carried out using the professional grade time-domain simulation software package EUROSTAG. The main feature of these computer programs is to propose a unique solution to various issues with a high degree of performance [6]. This single integrated program is able to simulate the full range of electrical phenomena, from transient to long term stability and gives continuous display for fast and slow events.

The numerical integration scheme is performed using a mixed Adams-BDF implicit integration method with automatic variable step size [7]. The differential and algebraic equations are solved simultaneously and the truncation error is evaluated in every step for determining the best step size. In practice, it automatically drops to values far bellow the smallest time constant, and when they diminish out, it gradually increases up to values larger than the smallest time constant of the whole system. 


\section{Load models}

\section{A. Static loads}

Static loads are generally represented by an exponential model in which the active and reactive power depend on voltage and frequency.

$$
\begin{aligned}
& P=P_{o}\left(\frac{U}{U_{o}}\right)^{\alpha}\left(\frac{\omega}{\omega_{\mathrm{o}}}\right)^{\delta} \\
& Q=Q_{o}\left(\frac{U}{U_{o}}\right)^{\beta}\left(\frac{\omega}{\omega_{\mathrm{o}}}\right)^{\gamma}
\end{aligned}
$$

$P_{o}$ and $Q_{o}$ are respectively the active and reactive loads supplied by the load flow program. $U$ denotes the busbar voltage [8], [9] and $U_{o}$ the busbar voltage at the initial conditions; $\omega$ is the angular velocity and $\omega_{o}$ is the synchronous speed.

In this study $\delta$ and $\gamma$ load model exponents are assumed equal to zero, since the power system frequency was considered constant. Table I present the different load models in accordance with the $\alpha$ and $\beta$ model parameters.

TABLE I. - Static load models

\begin{tabular}{|l|c|c|}
\hline \multicolumn{1}{|c|}{ Load Model } & $\alpha$ & $\beta$ \\
\hline Constant power & 0 & 0 \\
\hline Constant current & 1 & 1 \\
\hline Constant impedance & 2 & 2 \\
\hline
\end{tabular}

\section{B. Dynamic loads}

In this study it was only considered the double squirrel cage induction motors. The applied software assumes a balanced situation and the torque speed curve is approximated by a piece-wise linear function [10]. In figure 1 it is present a schematic representation of the induction motor.

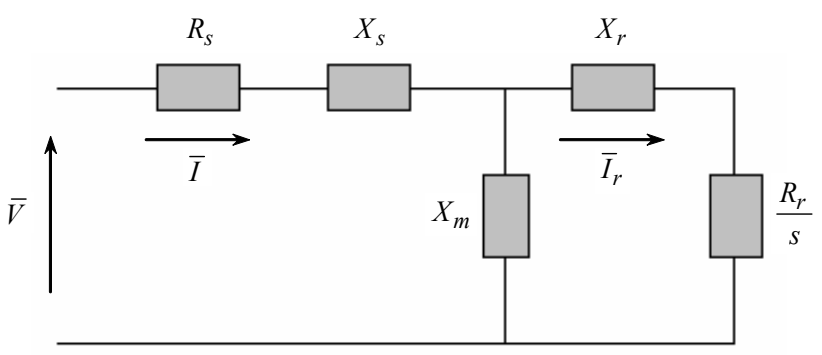

Fig. 1. Schematic representation of the induction motor

Table II shows the induction motor parameters used in this study. This dynamic load was connected to the busbar 8 of the test power network.
TABLE II. - Induction motor parameters

\begin{tabular}{|c|c|c|c|c|c|c|}
\hline Bus & $H$ [s] & $R_{S}$ [p.u.] & $X_{S}$ [p.u.] & $X_{m}$ [p.u.] & $R_{r}$ [p.u.] & $X_{r}$ [p.u.] \\
\hline 8 & 0.600 & 0.010 & 0.145 & 3.300 & 0.008 & 0.145 \\
\hline
\end{tabular}

In figure 1 and in table II $s$ is the motor slip; $H$ is the inertia constant; $R_{S}$ is the stator resistance; $X_{S}$ is the stator leakage reactance; $X_{m}$ is the rotor-stator mutual reactance; $R_{r}$ is the rotor resistance and $X_{r}$ is the rotor leakage reactance.

\section{Test power network}

In figure 2 it is shown the BPA test power network that was used in this study. The simulations were carried out considering the network data presented in [5], [11]. It was simulated the tripping of one of the five $500 \mathrm{kV}$ overhead transmission lines between busbars 6 and 7 at the time equal to $20 \mathrm{~s}$. The operating point assumed in this study corresponds to a $6855 \mathrm{MW}$ and $1046 \mathrm{MVAr}$ load level. Four scenarios were analysed as it is shown in table III. In all situations the load was always assumed as constant impedance in busbar 11 .

TABLE III. - Analysed scenarios

\begin{tabular}{|c|c|}
\hline Scenarios & Load models in busbar 8 \\
\hline Case I & Constant impedance \\
\hline Case II & Constant current \\
\hline Case III & Constant power \\
\hline Case IV & Induction motor \\
\hline
\end{tabular}

In all situations the ULTC regulation effect of the transformer connected between busbars 10 and 11 was taken into account. In every scenario it was analysed the overall system voltage stability. Generator $\mathrm{G}_{1}$ is considered as an infinite busbar, $\mathrm{G}_{2}$ and $\mathrm{G}_{3}$ are modelled in detail. The automatic voltage regulators of the generating units and the turbine speed governors were considered.

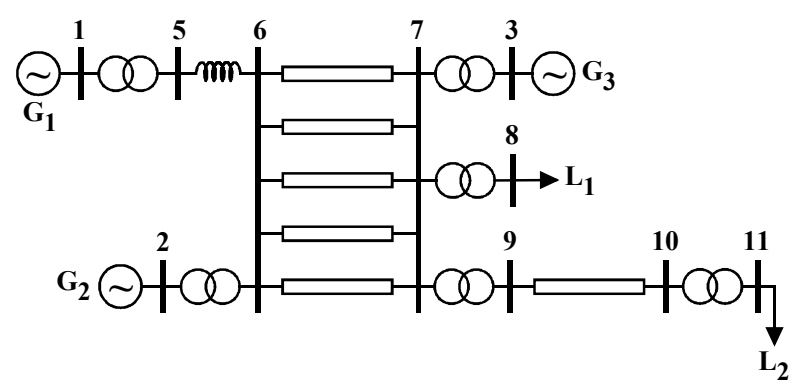

Fig. 2. BPA test power network single line diagram

\section{Results}

Figure 3 shows the voltage, the active and reactive load variation in busbar 8 (case I). Figure 4 presents the voltage variation in busbars 11 , ULTC position and the field current of the synchronous generators (case I). 


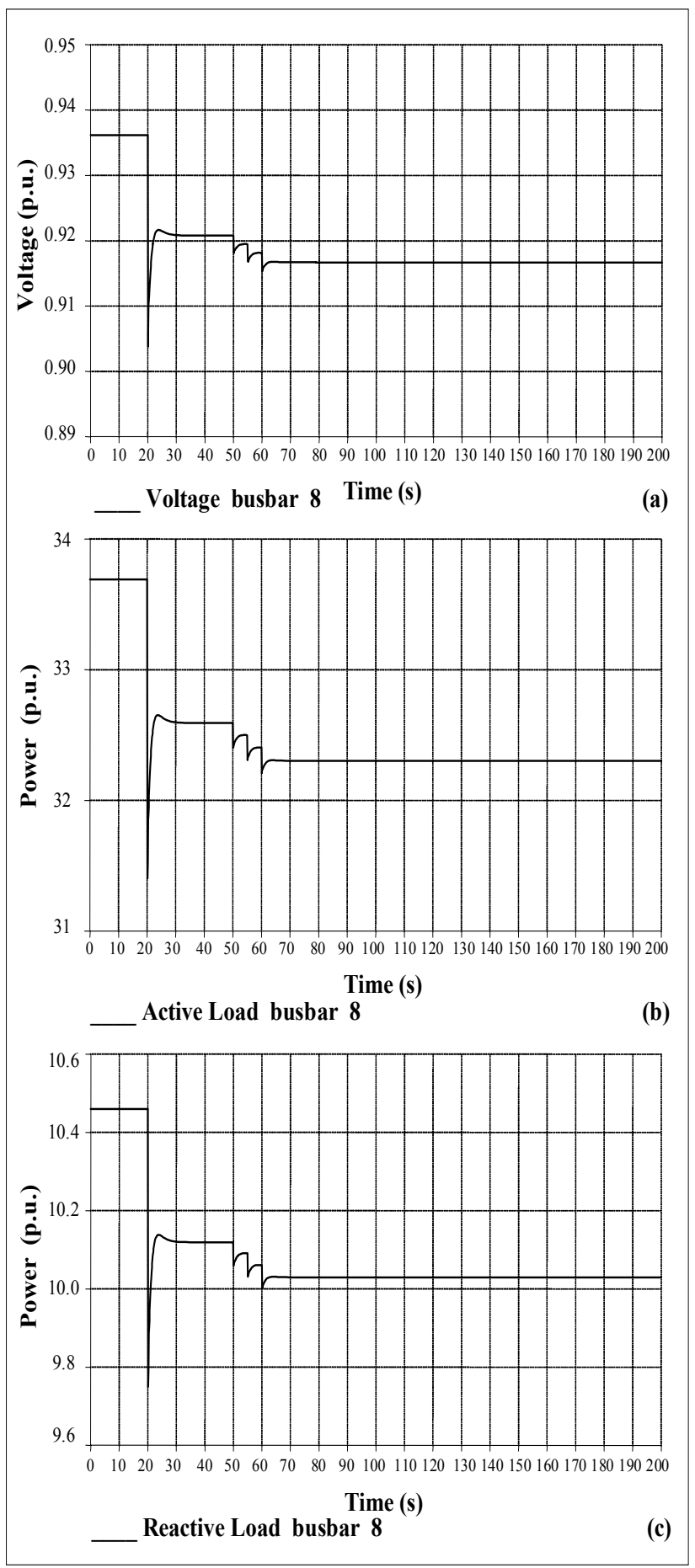

Fig. 3. (a) Voltage variation in busbar 8

(b) Active load in busbar 8

(c) Reactive load in busbar 8
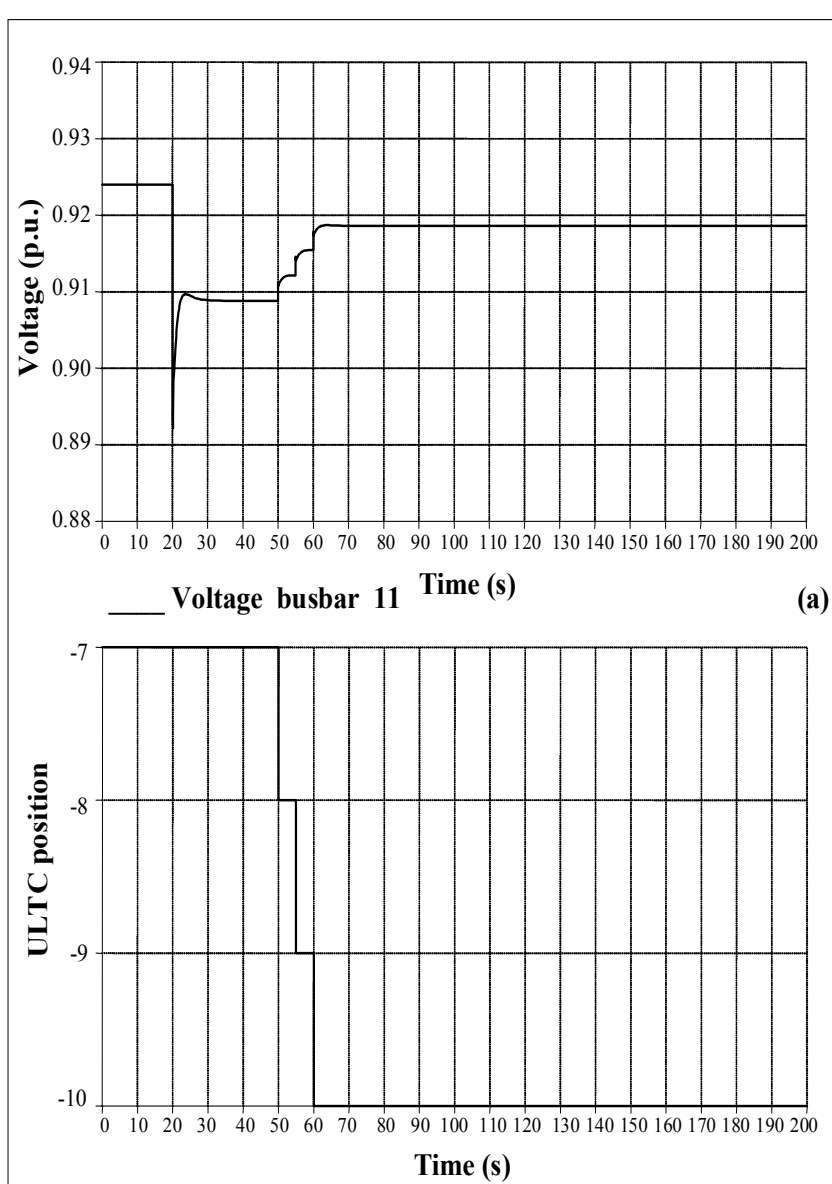

Transformer connected busbars 10 and 11

(b)

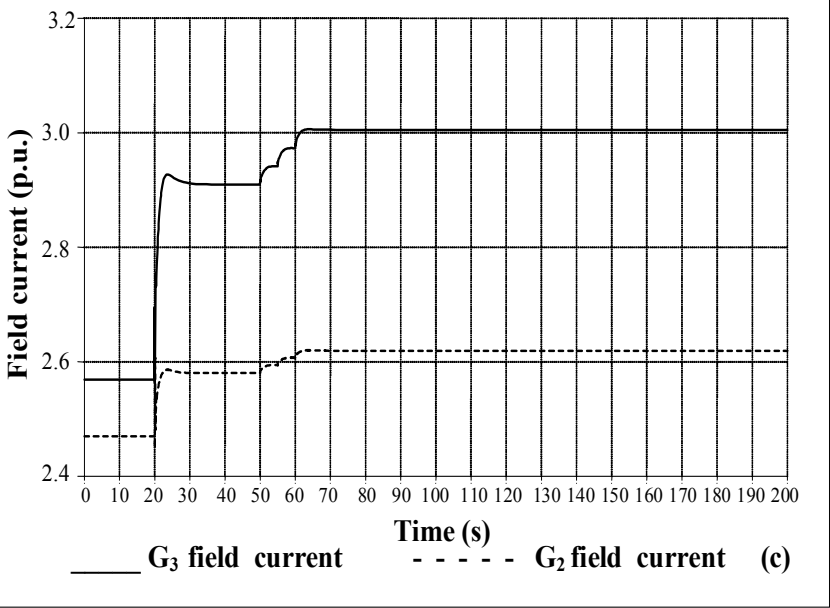

Fig. 4. (a) Voltage variation in busbar 11

(b) ULTC position

(c) $\mathrm{G}_{2}$ and $\mathrm{G}_{3}$ field currents 
Figure 5 shows the voltage, the active and reactive load trajectory in busbar 8 (case II). Figure 6 presents the voltage variation in busbars 11 , ULTC position and the field current of the synchronous generators (case II).
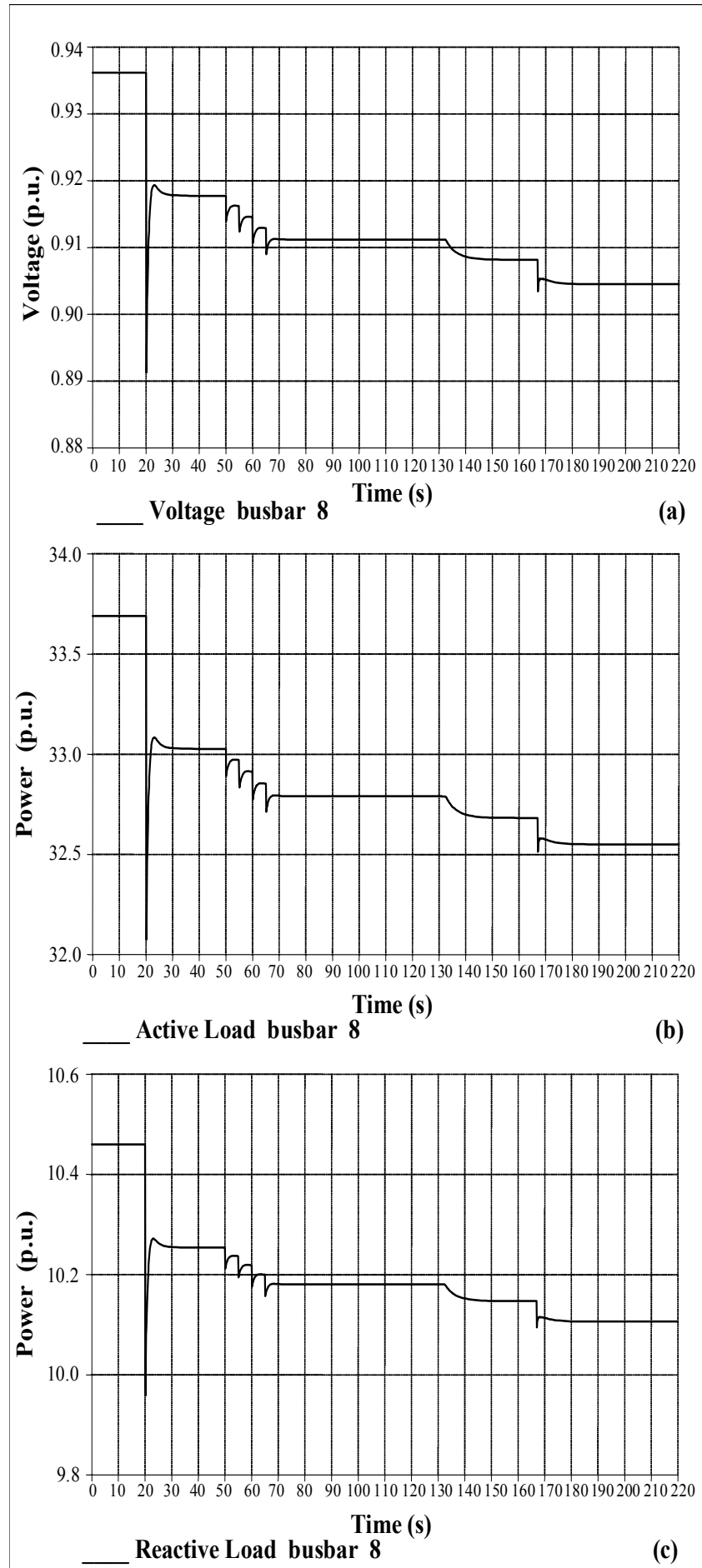

Fig.5. (a) Voltage variation in busbar 8

(b) Active load in busbar 8

(c) Reactive load in busbar 8
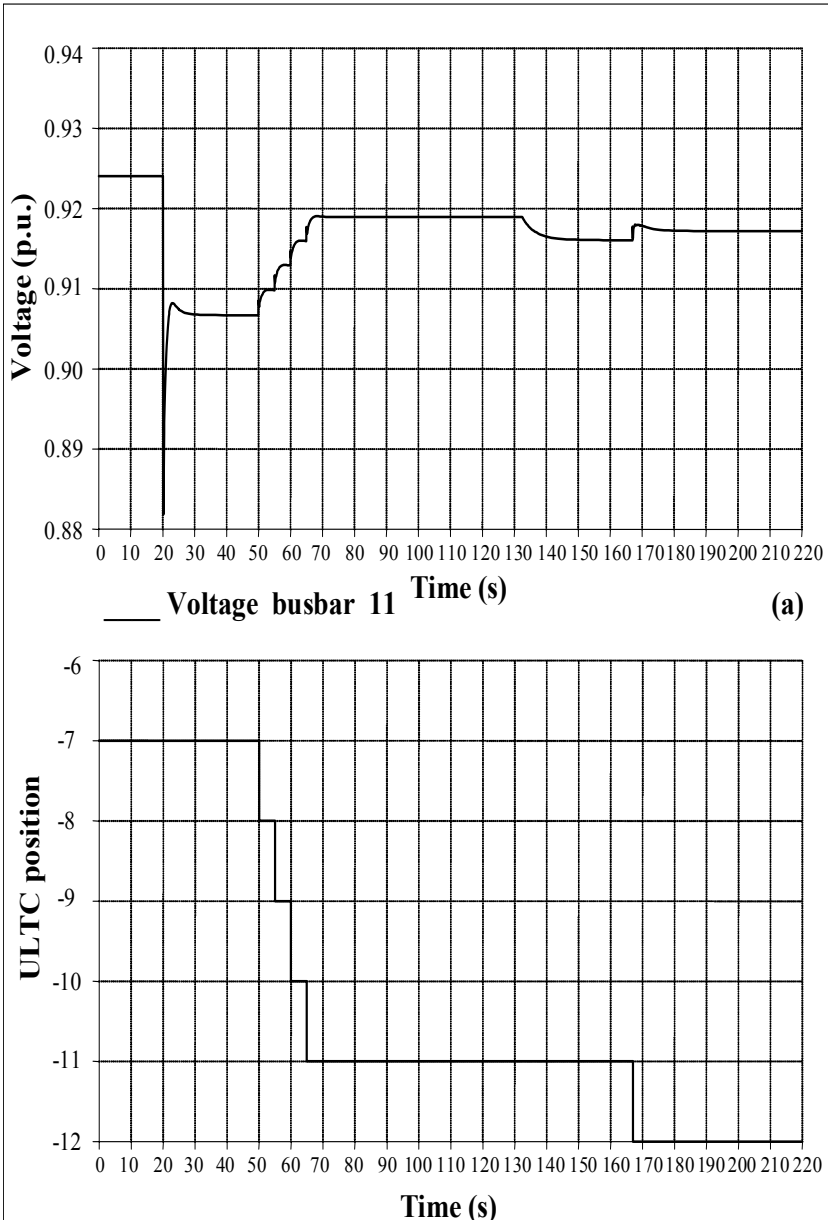

Transformer connected busbars 10 and 11

(b)

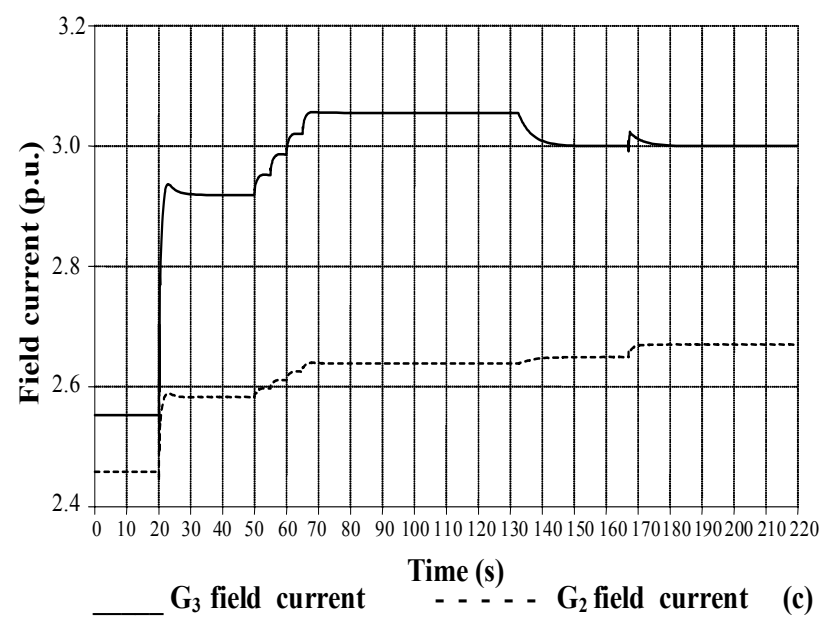

Fig.6. (a) Voltage variation in busbar 11

(b) ULTC position

(c) $\mathrm{G}_{2}$ and $\mathrm{G}_{3}$ field currents 
Figure 7 shows the voltage, the active and reactive load variation in busbar 8 (case III). Figure 8 presents the voltage variation in busbars 11 , ULTC position and the field current of the synchronous generators (case III).
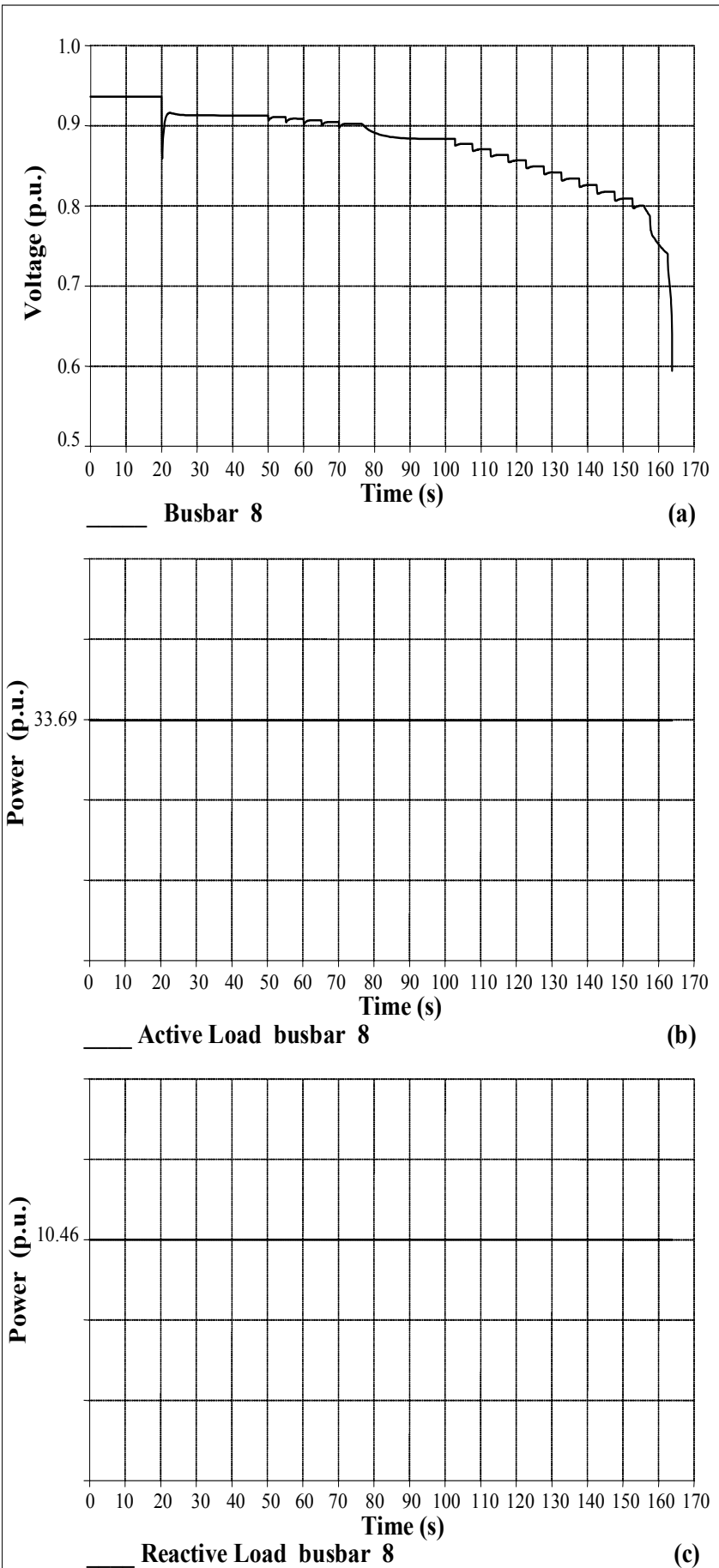

Fig.7. (a) Voltage variation in busbar 8

(b) Active load in busbar 8

(c) Reactive load in busbar 8
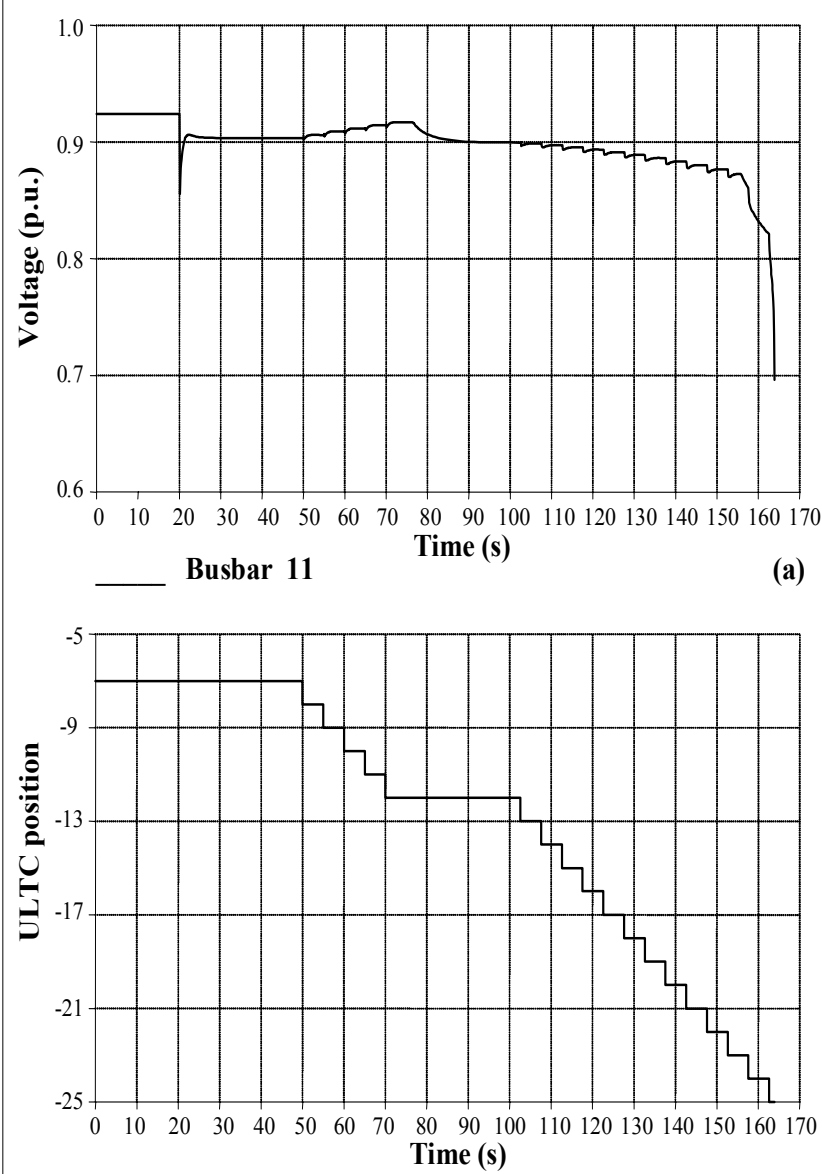

__ Transformer connected busbars 10 and 11

(b)

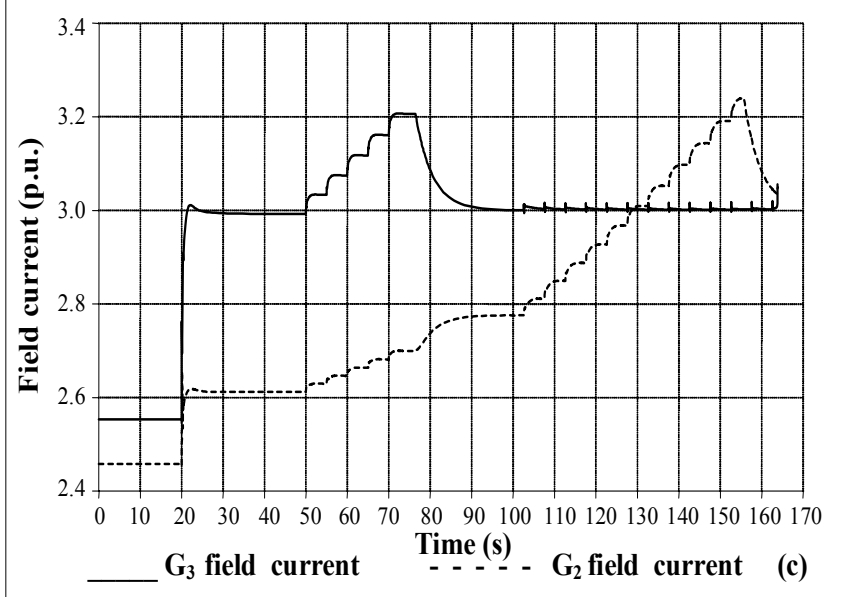

Fig. 8. (a) Voltage variation in busbar 11

(b) ULTC position

(c) $G_{2}$ and $G_{3}$ field currents 
Figure 9 shows the voltage, the active and reactive load variation in busbar 8 (case IV). Figure 10 presents the voltage variation in busbars 11 , ULTC position and the field current of the synchronous generators (case IV).
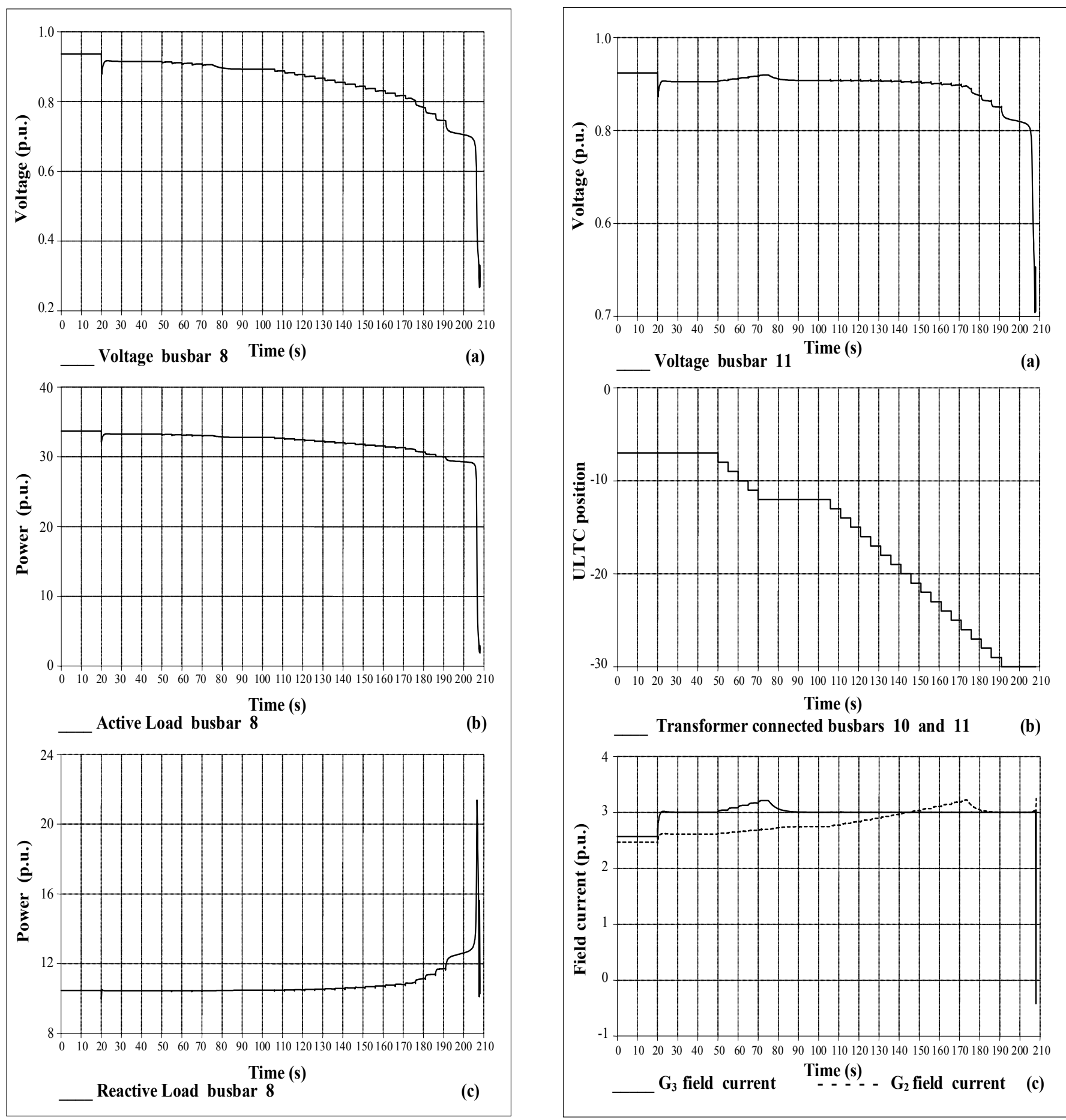

Fig. 9 (a) Voltage variation in busbar 8

(b) Active load in busbar 8

(c) Reactive load in busbar 8

Fig.10. (a) Voltage variation in busbar 11

(b) ULTC position

(c) $\mathrm{G}_{2}$ and $\mathrm{G}_{3}$ field currents 


\section{Conclusions}

In this paper it was studied and analysed the influence of the load models in the dynamic voltage stability assessment of an electric power system. For the tripping simulation of one of the five $500 \mathrm{kV}$ overhead transmission lines between busbars 6 and 7 a voltage collapse arises in the cases III and IV. Case II presents more transients than case I, although both situations are stable. If a voltage dip arises in an induction motor then a small decrease of the active power occurs while the reactive power increases drastically. From the above results it is pointed out that accurate load models play a very important role in the dynamic voltage stability analysis in order to specify control actions.

\section{References}

[1] C. W. Taylor, "Power System Voltage Stability", New York, McGraw Hill, 1994.

[2] V. Vittal, "Consequence and Impact of Electric Utility Industry Restructuring on Transient Stability and Small Signal Stability Analysis", in Proc. of the IEEE special issue on the Technology of Power System Competition, Vol. 88, No.2, pp. 196-207, February 2000.

[3] T. Van Cutsem, "Voltage Instability: Phenomena, Countermeasures and Analysis Methods", in Proc. of the IEEE special issue on the Technology of Power System Competition, Vol. 88, No. 2, pp. 208-227, February 2000.
[4] CIGRE Task Force 38-02-12, "Criteria and Countermeasures for Voltage Collapse", October 1995.

[5] R. M. Monteiro Pereira, C. Machado Ferreira, J. A Dias Pinto and F. P Maciel Barbosa, "Influence of the ULTC on the dynamic voltage stability of an electric power system", in Proc. of the $8^{\circ}$ Congresso Luso Espanhol de Engenharia Electrotécnica, 8 CLEEE, Vilamoura, Portugal, Vol. 2, pp. 4.77-4.82, July 2003.

[6] O. Fillâtre, C. Evrard et al., "A powerful tool for dynamic simulation of unbalanced phenomena", in Proc. of the International Conference on Advances in Power System Control, Operation and Management, Hong Kong, Vol. 2, pp. 52-6 531, November. 1997.

[7] J. Y Astic and M. Jerosolimski, "The mixed Adams BDF variable step size algorithm to simulate transient and long-term phenomena in power systems", IEEE Transactions on Power Systems, Vol. 9, No. 2, pp. 929-935, May 1994.

[8] S. A. Y. Sabir, D. C. Lee, "Dynamic load models derived from data acquired during system transients", IEEE Transactions on Power Apparatus and Systems, Vol. PAS-101, No.9, pp.3365-3372, September 1982.

[9] A. Borghetti, R. Caldon, A. Mari, C. A. Nucci, "On dynamic load models for voltage stability studies", IEEE Transactions on Power Systems, Vol. 12, No. 1, pp. 293-303, February 1997.

[10] Tractebel and Electricité de france, "EUROSTAG", User's Manual, December 2000.

[11] Stubbe, M., et al., "Tools for simulating long term dynamics", ELECTRA, No. 163, pp. 150-166, December 1995. 